\title{
TBP-Associated Factor Gene
}

National Cancer Institute

\section{Source}

National Cancer Institute. TBP-Associated Factor Gene. NCI Thesaurus. Code C20539.

Control of transcription by RNA polymerase involves the basal transcription machinery, a collection of proteins which include TFIIB, TFIIE, TFIIF, TATA-box binding protein (TBP), TFIIA and TAF1. These, with RNA polymerase II, assemble into complexes which are modulated by transactivator proteins that bind to cis-regulatory elements located adjacent to the transcription start site. Some modulators interact directly with the basal complex, whereas others may act as bridging proteins linking transactivators to the basal transcription factors. Some of these associated factors are weakly attached while others are tightly associated with TBP in the TFIID complex. Among the latter are the TBPassociated factors (TAFs) encoded by these TBP-Associated Factor Genes. Different TAFs may mediate the function of distinct transcriptional activators for a variety of gene promoters and RNA polymerases. (from OMIM 600772 and $\mathrm{NCl}$ ) 